University of Wollongong

Research Online

Faculty of Engineering and Information

Faculty of Engineering and Information

Sciences - Papers: Part A

Sciences

$1-1-2013$

Teamwork as a service: a cloud-based system for enhancing teamwork performance in mobile learning

Geng Sun

University of Wollongong, gs147@uowmail.edu.au

Jun Shen

University of Wollongong, jshen@uow.edu.au

Follow this and additional works at: https://ro.uow.edu.au/eispapers

Part of the Engineering Commons, and the Science and Technology Studies Commons

Research Online is the open access institutional repository for the University of Wollongong. For further information contact the UOW Library: research-pubs@uow.edu.au 


\title{
Teamwork as a service: a cloud-based system for enhancing teamwork performance in mobile learning
}

\begin{abstract}
Although cloud computing helps learners to access online learning content through commonly used devices, it can be difficult to collaborate in the mobile environment. We develop a service-oriented system, 'Teamwork as a Service' (TaaS), to facilitate learners' team learning activities. The five main services of TaaS facilitate a teamwork-enhanced learning flow associated with the theory of Kolb's team learning experience, providing learners with an introduction, a 'jigsaw classroom', schedule planning, and mutual supervision during the whole process. Specifically, TaaS enables a rational grouping mechanism that allocates learners to their appropriate tasks in order to give their best performance. TaaS is implemented on the Amazon EC2 cloud, and is proven to work with cloud-hosting learning management systems.
\end{abstract}

\section{Keywords}

learning, enhancing, mobile, teamwork, service, performance, cloud, system

\section{Disciplines}

Engineering | Science and Technology Studies

\section{Publication Details}

Sun, G. \& Shen, J. (2013). Teamwork as a service: a cloud-based system for enhancing teamwork performance in mobile learning. IEEE International Conference on Advanced Learning Technologies (pp. 376-378). IEEE Xplore: IEEE. 


\title{
Teamwork as a Service: a Cloud-based System for Enhancing Teamwork Performance in Mobile Learning
}

\author{
Geng Sun, Jun Shen \\ Faculty of Informatics, University of Wollongong \\ Wollongong, NSW, Australia \\ Email: gs147@uowmail.edu.au, jshen@uow.edu.au
}

\begin{abstract}
Although cloud computing helps learners to access online learning content through commonly used devices, it can be difficult to collaborate in the mobile environment. We develop a service-oriented system, 'Teamwork as a Service' (TaaS), to facilitate learners' team learning activities. The five main services of TaaS facilitate a teamwork-enhanced learning flow associated with the theory of Kolb's team learning experience, providing learners with an introduction, a 'jigsaw classroom', schedule planning, and mutual supervision during the whole process. Specifically, TaaS enables a rational grouping mechanism that allocates learners to their appropriate tasks in order to give their best performance. TaaS is implemented on the Amazon EC2 cloud, and is proven to work with cloud-hosting learning management systems.
\end{abstract}

Keywords-mobile cloud-based learning;enhancing teamwork performance; task allocation; service-oriented system.

\section{INTRODUCTION}

The application of mobile cloud-based learning is gaining wide acceptance [1], which is very useful for learners, enabling them to learn wherever they are and whenever they want and making up the limitation of mobile devices.

The concept of service-oriented systems is being adopted because of its strengths in the standardization of smooth interactions among different systems and the reuse of legacy systems [2]. In addition, making use of Web 2.0 technologies, several of the latest learning management systems (LMSs) are able to offer collaborative learning tools. With they are hosted in the cloud and available for mobile access, it is possible for multiple learners to work together towards a common target by using mobile cloud-based learning.

On the other hand, to our knowledge, although team learning happens more and more frequently in the mobile cloud-based learning environment, there are still comparatively few studies focusing on enhancing teamwork performance in this novel environment. In this paper, we introduce a novel approach to fill this gap in research, by offering a service-oriented system, 'Teamwork as a Service' (TaaS), which works as a third-party system by adding teamwork-focused functions to current cloud-hosting LMSs.

\section{Motivation AND METHODOLOGY}

The context of mobile cloud-based learning is more specific than traditional learning, where learners are distributed over large geographical areas. These virtual teams are more focused on task-related outcomes and time constraints [3]. Thus, learners are faced with many unpredictable difficulties in team learning for which they are not prepared and perhaps the biggest of these is insufficient communication [4].

In addition to this, there are problems which also occur in traditional team learning which can negatively affect mobile team learning. The literature shows that learners belonging to the same team often have differing learning styles and therefore require diverse learning approaches [5]. Each learner's expectations and preferences also influence their motivation to work to the limit of their abilities [6].Current assessment criteria also lack the mechanism to track the entire learning experience.

Learning activities of mobile cloud-based learning normally consist of two sections: online learning and offline learning [7]. Using online systems to command and restrain offline behaviors helps to avoid confusion and misunderstanding, while offering more offline opportunities. In addition, the needs for data and computation during the team learning process can be controlled by the cloud, thus the complexity of system will not be aggravated by the limitations of the mobile devices.

Using Kolb's team learning experience (KTLE) as the main concept [8], we implemented a teamwork-enhanced learning flow within our newly designed service-oriented system, TaaS [9]. TaaS works in conjunction with cloud-hosting LMSs, and emphasizes building a better context for team learning.

\section{SERVICES DESIGN}

\section{A. The Survey Service}

For "introduction to teams", the Survey Service offers interfaces to learners for answering questions in order to investigate their capabilities. The survey is in single-answer multiple-choice format and can be operated as self-assessment or peer-assessment. There are five sets of questions coming from [10] [11], which are pre-installed in the Survey Service, four of which are for the four aspects (accommodating, assimilating, converging, diverging) of Kolb's learning style (KLS) [12][13], and the last is for comprehensive teamwork skills.

\section{B. The Jigsaw Service}

The three stages of the jigsaw method are imitated by the Jigsaw Service [14]. For "initial discussion in original team", it groups learners into four-person original teams, keeping 
the total comprehensive teamwork skills of each equal with the others'. In each original team, the four KLS team roles are separately assigned to members [15]. For "joining expert team to refine cognition", it rebuilds four expert teams, within each of which learners who played the same roles in the original teams are involved. For "backing to original group to teach others what was gained in expert group", it redirects learners into the original teams from which they have come.

\section{The Bulletin Service}

The Bulletin Service provides a platform for learners to collaboratively define the "team context" and on which they are able to publish schedules of alternative tasks, each of which is suitable for an imaginary team and consists of several subtasks. The publisher of a task is required to mark the difficulty of its subtasks as expected-achievable values in KLS, while other learners are free to show their preferences regarding those when browsing. As it is in WYSIWYG mode, publishing the task schedule through user interface is easily done. In addition, subtasks' difficulty and learners' preferences are also marked using a multiple-choice format.

\section{The Inference Service}

For "team role" and "team membership", the Inference Service works like a team leader who assigns each learner a subtask, and also groups learners who take subtasks belonging to the same task into a team. This is the core of TaaS because it makes rational decisions to cover the uncertainty of the mobile environment, concentrating on outlining learners' responsibilities clearly and bringing their strengths into full play. The mathematical model of the task allocation is shown in Table I. Five values $A C^{k}, A S^{k}, C^{k}, D^{k}$ and $C T^{k}$ represent the capability values of accommodating, assimilating, converging, diverging and comprehensive teamwork skills, respectively.

The teamwork-enhanced task allocation is realized by simulated annealing algorithm (SA) [16]. The operation of $\mathrm{SA}$ is to use simulated annealing regulation to optimize a set of initial solutions, iteration by iteration, towards an ultimate purpose for each, which is described by an objective function. The initial solution is a random array of $k$ learner/subtask pairs, where $k$ is the number of learners. A new solution is generated by swapping the positions of learners of two learner/subtask pairs in a previous solution.

We suppose two scenarios where teams can be formed either by "keeping the balance among each team" or by "letting the learners show their capabilities mostly". Solutions in the two scenarios should be measured by (1) or (2), respectively. The ultimate solution will not be reached until achieving the lowest value of $R_{m}$ :

$$
\begin{aligned}
& R_{m}=\operatorname{Min}(\alpha \operatorname{VarCT}+\beta \operatorname{VarDeP}+\gamma \operatorname{VarDeK}+\varepsilon \overline{\operatorname{DeP}}+\eta \overline{\operatorname{DeK}}) \\
& R_{m}=\operatorname{Min}(\alpha \operatorname{VarCT}+\beta \operatorname{SumDeP}+\gamma \operatorname{SumDeK})
\end{aligned}
$$

In both equations, each Greek letter denotes the weight of its corresponding attribute.

\section{E. The Monitor Service}

The Monitor Service aims to provide mutual supervision for "team process" and "team action". In each team, each learner is assigned as the coordinator for another. The pair of completer/coordinator is linked by a file transmission channel, through which the completer sends his periodical outcome to the coordinator, who takes responsibility for judging whether he has reached an acceptable rate of progress and is capable of continuing or not, by grading him "satisfactory" or "unsatisfactory" . A penalty mechanism is embedded in this service. It automatically deducts the completer's marks if he gets any "unsatisfactory" grade on a stage of his work in progress.

\section{SYSTEM IMPLEMENTATION}

To implement TaaS, we have launched a Linux instance, of the Amazon Elastic Cloud Computing (EC2). We have configured the server environment as Apache + PHP + Mysql, and hosted our TaaS package on it. We have uploaded an open-source LMS, MOODLE, into the Amazon EC2, hosted on the same instance.

We have integrated the five services introduced in Section III as a system and added a user-management module for controlling accounts. The single-sign-on (SSO) technique is realized to enable users (teachers and learners) to $\log$ in to TaaS if they have valid MOODLE accounts. We created a new database of TaaS for storing teamwork-related data, such as learners' KLS capabilities, preferences, etc, meanwhile basic learning information are invoked from

\begin{tabular}{|c|c|c|}
\hline Element & Definition & Notation \\
\hline$L^{k}$ & The $\mathrm{k}^{\text {th }}$ Learner & Learner ID \\
\hline Task $^{i}$ & The $\mathrm{i}^{\text {th }}$ Task & Task ID \\
\hline Suntask $k^{i j}$ & The $\mathrm{j}^{\text {th }}$ Subtask of the $\mathrm{i}^{\text {th }}$ Task & Subtask ID \\
\hline$K L S^{k}$ & $L^{k}$ s survey results of KLS capability & $K L S^{k}=\left\{A C^{k}, A S^{k}, C^{k}, D^{k}\right\}$, each value is a real between 1 and 10 \\
\hline$C T^{k}$ & $L^{k, s}$ survey results of comprehensive teamwork capability & $C T^{k}$ is a real between 1 and 10 \\
\hline$P_{k}^{i j}$ & $L^{k, s}$ preference to the Suntask $k^{i j}$ & $P_{k}^{i j}$ is an integer between 1 and 5. \\
\hline$S T^{i j}$ & Suntask $^{i j}$ 's expected-achievable degree in KLS & $S T^{i j}=\left\{A C^{i j}, A S^{i j}, C^{i j}, D^{i j}\right\}$, each value is a real between 1 and 10 \\
\hline$N^{i}$ & The number of subtask in the $\mathrm{i}^{\text {th }}$ Task & $N^{i}$ is a integer greater than 0 \\
\hline$D e P_{k}^{i j}$ & The preference gap between $L^{k \text { s }}$ s ideal and reality. & $D e P_{k}^{i j}=5-P_{k}^{i j}$ \\
\hline$D e K_{k}^{i j}$ & $\begin{array}{l}\text { The deviation of } L^{k} \text {, } \text { SLS capability values versus } \\
\text { Suntask } k^{i j} \text {,s KLS expected-achievable degree. } \\
\text { (Note the deviation is defined by the expression of Euclidean } \\
\text { distance. It is the lower the better. An ideal value for it is } \\
\text { below } 0 \text {.) }\end{array}$ & $\begin{array}{l}\operatorname{DeK}_{k}^{i j}=-\left\{\operatorname{sign}\left[\sum\left(K L S^{k}-S T^{i j}\right)\right]\right\} \cdot\left\|K L S^{k}-S T^{i j}\right\|, \text { subject to: } \\
K L S^{k}-S T^{i j}=\left\{A C^{k}-A C^{i j}, A S^{k}-A S^{i j}, C^{k}-C^{i j}, D^{k}-D^{i j}\right\} \\
\left\|K L S^{k}-S T^{i j}\right\|=\sqrt{\left(A C^{k}-A C^{i j}\right)^{2}+\left(A S^{k}-A S^{i j}\right)^{2}+\left(C^{k}-C^{i j}\right)^{2}+\left(D^{k}-D^{i j}\right)^{2}}\end{array}$ \\
\hline
\end{tabular}

TABle I. Problem Setting and Definition for Computing in The Inference Service 
MOODLE through its web service APIs. In addition, the new database exposes a web service API for remotely invoking from LMSs other than MOODLE. After any change of team information, TaaS automatically updates it to MOODLE.

The UI of teachers' and learners' main page of TaaS are shown as Figure 1 and Figure 2, respectively.

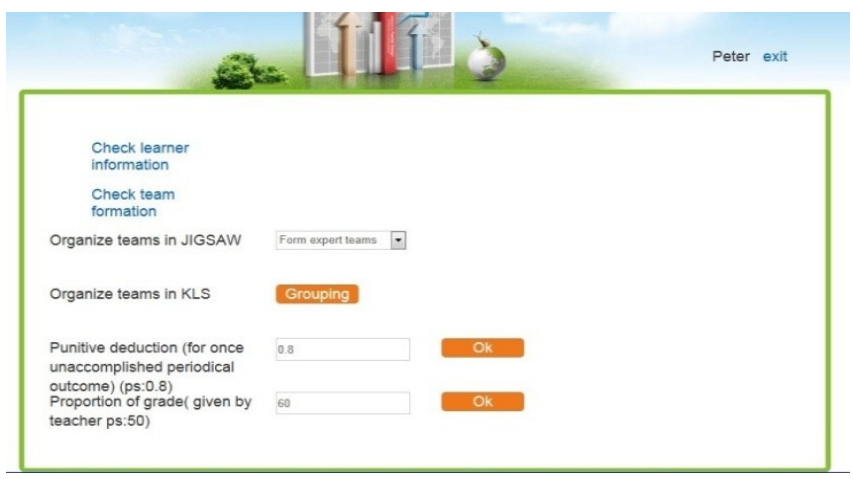

Figure 1. Main Page of the Teacher User

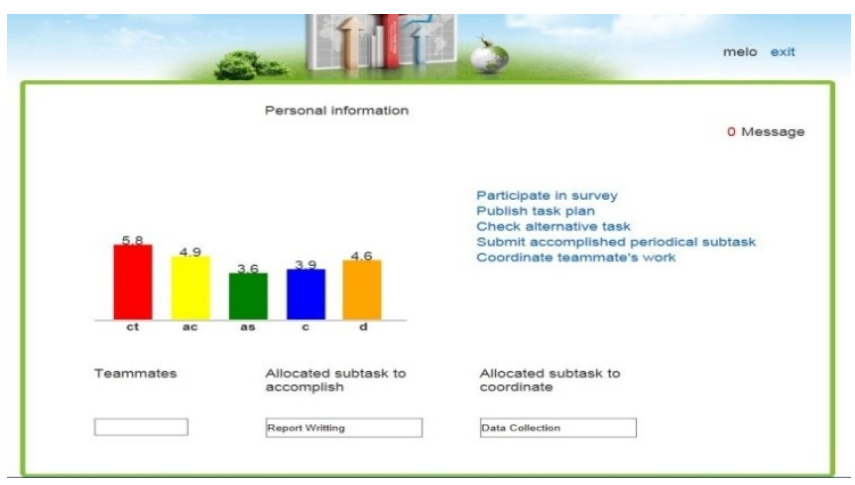

Figure 2. Main Page of the Learner User

As shown in Figure 3, once the topics of team learning assignments are released, the first synchronization between TaaS and cloud-hosting LMSs is triggered. Both of them will share the same user information over the whole team learning process.

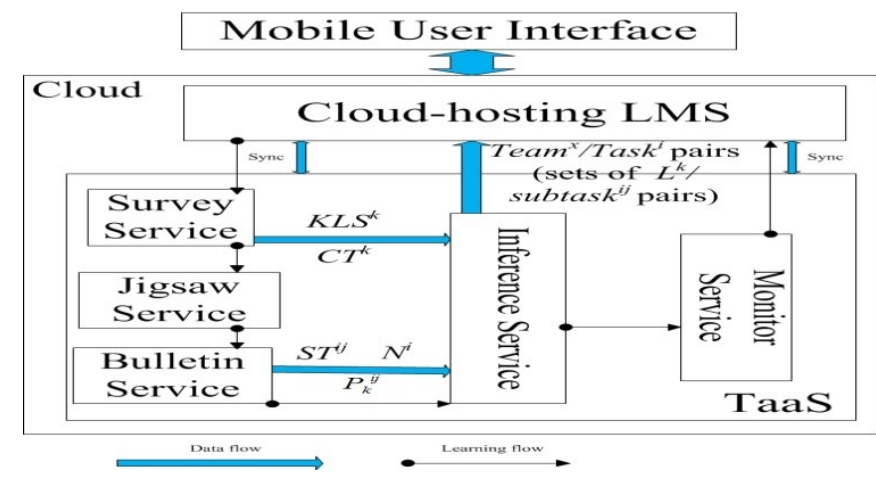

Figure 3. System Framework of TaaS

\section{CONCLUSSION}

In this paper, we introduce a service-oriented system, TaaS, which is associated with cloud-hosting LMSs in order to establish a teamwork-enhanced learning flow. TaaS will be of significant help to learners who are engaged in teamwork using mobile devices. The five services of TaaS concentrate on covering the gaps caused by the characteristics of mobile environments, making it easy to organize the necessary learner information gathering, efficient discussion, schedule planning and mutual supervision. In particular, combining learners' capabilities, preferences and subtask difficulties, TaaS provides a novel model of task allocation, which is optimized by the simulated annealing algorithm. We have implemented TaaS on the Amazon EC2 cloud. In future research, we will bring in case studies to evaluate how much learners' teamwork performance has been enhanced through the use of TaaS.

\section{REFERENCES}

[1] N. M. Rao, "Cloud Computing Through Mobile-Learning", International Journal of Advanced Computer Science and Applications, vol. 1, no. 6, pp. 42-47, 2010

[2] F-F, Chua and E-S, Tay, "Developing Virtual Learning Environment 2.0 Using Web Services Apporach". 12 ${ }^{\text {th }}$ IEEE International Conference on Advanced Learning Technologies, Rome, Italy, July, 2012.

[3] C. S. Saunders and M. K. Ahuja, "Are All Distributed Teams the Same? Differentiating Between Temporary and Ongoing Distributed Teams". Small Group Research. vol.37, no.6, pp.662-700, 2006.

[4] A. Kukulska-Hulme, M. Sharples, M. Milrad, I. Arnedilo-Sanchez and G. Vavoula, "Innovation in Mobile Learning: A European Perspective", International Jounal of Mobile and Blended Learning (IJMBL), vol. 1, no. 1, pp. 13-35, 2013.

[5] B. Feldmann, "Group Types in e-Learning Environments-Study Team, Working Team and Learning Team", $7^{\text {th }}$ International Conference on Information Technology Based on Higher Education and Trainning (ITHET), Ultimo, Australia, July, 2006.

[6] T. Wu, D. Liu and X. Bi, "Team Learning Orientation and Conflicts Influence Team Performance in Different task Difficulties", IEEE International Conference on Advanced Management Science, Chengdu, China, 2006.

[7] A. Trifonova and M. Ronchetti, "Mobile Learning: Is Anytime + Anywhere $=$ Always Online?", $6^{\text {th }}$ IEEE International Conference on Advanced Learning Technologies, Kerkrade, Netherlands, July, 2006.

[8] A. B. Kayes, D. C. Kayes and D. A. Kolb, 'Developing teams using the Kolb team learning experience'. Simulation \& Gaming, vol. 36, pp. 355-363, 2005.

[9] X. M. Cao, P. Zhao and X. Wang, "Study on Design and Development e-Learning System Based on Learning Flow", World Congress on Software Engineering (WCSE), China, May, 2009.

[10] S. A. Wheelan, Creating Effective Teams : A Guide for Members and Leaders, Sage Publications, 2005.

[11] R. Lingard, "Teaching and Assessing Teamwork in Engineering and Computer Science", Proceeding of International Symposium on Engineering Education and Educational Technologies(EEET) , Orlando, USA, July 2009.

[12] D. Kolb, Experiential learning: Experience as a source of learning and development. Upper Saddle River, NJ: Prentice Hall, 1984.

[13] A. Y. Kolb and A. D. Kolb, "Learning styles and learning spaces: Enhancing experiential learning in higher education". Academy of Management Learning and Education. vol.4, no.2, pp193-212, 2005.

[14] E. Aronson, N. Blaney, C. Steophan, J. Sikes and M. Snapp, The Jigsaw Classroom, Beverly Hills, CA, USA, 1978.

[15] R. Belbin, Team Roles at Work, Butterworth Heinemann, 1993.

[16] G. Sun and J. Shen, "Evaluations of Heuristic Alogrithms for Teamwork-Enhanced Task Allocation in Mobile Cloud-based Learning", $17^{\text {th }}$ IEEE International Conference on Computer Supported Cooperative Work in Design (CSCWD), Whistler, BC, Canada, June, 2013. 